\title{
A NATUREZA ENQUANTO ATRAÇÃO E REPULSÃO NO MUNICÍPIO DE ANGRA DOS REIS - RJ
}

\section{NATURE AS ATTRACTION AND REPULSION IN THE CITY OF ANGRA DOS REIS - RIO DE JANEIRO STATE}

\author{
Eluan Alan Lemos Pocidonio \\ Graduando em Geografia/UFRJ \\ Bolsista PIBIC-CNPq/UFRJ \\ eluanlemos@yahoo.com.br \\ Telma Mendes da Silva \\ Doutora em Geografia/UFRJ \\ Profa. Adjunta - Depto. Geografia/UFRJ \\ telmendes@globo.com
}

\begin{abstract}
RESUMO
O município de Angra dos Reis (RJ) é caracterizado tanto pela beleza de sua paisagem, como por uma susceptibilidade natural dos terrenos à ocorrência de movimentos gravitacionais de massa, que somados aos elevados índices pluviométricos, característicos principalmente dos meses de verão, tem o principal agente deflagrador destes episódios e que às vezes tomam dimensões catastróficas na área. Neste artigo busca-se debater a questão da paisagem enquanto fator de atração turística, além de levantar a necessidade de conhecimento em relação à fragilidade ambiental frente à conservação do patrimônio natural e ao bem-estar da população e da economia local. Ressalta-se que a morfologia caracterizada por apenas 7,45\% de áreas planas e $84,17 \%$ de serras, tem no terreno sérias dificuldades pelo município, tanto ao que se refere a um crescimento desordenado, que cresce em direção a áreas extremamente frágeis de elevadas declividades, como aos aspectos associados à intensidade e frequência dos eventos de enchentes e/ou de movimentos gravitacionais de massa que ocorrem em função das características do contraste abrupto dado pela morfologia local. Neste trabalho, serão discutidos ainda os eventos de grandes magnitudes registrados nos anos de 2002 e 2010, e que gerou uma série de transtornos à população local e turistas, bem como desestabilizou diversos setores da economia.
\end{abstract}

Palavras-chave: Turismo, Geografia, Paisagem, Fragilidade Ambiental, Angra dos Reis

\begin{abstract}
Angra dos Reis (Rio de Janeiro state) is characterized by the beauty of its landscape, but also by its natural susceptibility to occur landslides, which added to high volume precipitation events, especially during the summer, becomes the main agent of these events that often have catastrophic dimensions. This article tries to debate the landscape as a factor that may attracts tourists, besides discussing the need of understanding the environmental fragility looking forward the conservation of the natural wealth and the
\end{abstract}


well-fare of the inhabitants and the local economy. It's important to notice that the morphology of the area, characterized by only $7.45 \%$ of flat areas and $84.17 \%$ of mountains, has over the land serious difficulties, either on the aspect of the fast and uncontrolled growth of the city, expanding directly into extremely fragile areas with high slopes, or the aspects related to the intensity and frequency of the flooding events and/or the landslides that occur because of the morphology characteristics. This paper will also discuss the events of great magnitude in the years of 2002 and 2010, responsible for series of problems to the local inhabitants and tourists, as well as harming several economy sessions.

Key-words: Tourism, Geography, Landscape, Environmental Fragility, Angra dos Reis.

\section{INTRODUÇÃO}

O município de Angra dos Reis, pertencente ao litoral sul do Rio de Janeiro e inserido na região da 'Costa Verde', possui no turismo importante vocação econômica, impulsionado principalmente por sua paisagem mundialmente divulgada e conhecida. A beleza natural é o fator da grande atratividade, no entanto eventos de chuvas intensas que comumente ocorrem nesta área ocasionaram no início de 2010 uma série de eventos de movimentos gravitacionais de massa, que são resultantes também da elevada fragilidade natural da morfologia local. Turistas e moradores foram vitimados pelos efeitos desses eventos, e que foram recorrentes na área até o mês de abril do referido ano. Em sua maioria, os locais mais afetados se localizaram ao longo da Rodovia BR101 (Rio-Santos), que é a principal via de acesso e que corta longitudinalmente toda a área.

O presente trabalho tem como meta trazer para o debate do turismo a questão da fragilidade ambiental da área. Além disto, justificativa-se este estudo pelo fato de que em momentos de ocorrência destes eventos evolutivos da paisagem se associarem uma desestruturação da economia local, que tem na atividade turística importante fonte de geração de recursos. Para tanto, teremos como exemplo os eventos 'catastróficos' ocorridos tanto no ano de 2010, quanto os referentes ao ano de 2002.

O trabalho baseou-se nas seguintes etapas de pesquisa: uma contextualização de temas abordados, a fim de compor uma base teórico-conceitual; caracterização das unidades morfológicas presentes no município de Angra dos Reis através de consulta ao mapa geomorfológico realizado por Silva (2002); resgate nos arquivos fotográficos 
existentes no Núcleo de Estudos do Quaternário e Tecnógeno (NEQUAT/IGEO-UFRJ) das ocorrências para o ano de 2002; levantamento sistemático dos atrativos turísticos, tendo como objetivo identificá-los para posterior avaliação, empregando uma adaptação da metodologia desenvolvida por AGB Engenharia e Meio Ambiente Ltda. (2008) e realização de campanhas de campo para o reconhecimento de feições morfológicas identificadas no mapa elaborado, aspectos geológico-geomorfológicos de susceptibilidades locais, etapas de acompanhamento e realização de documentação fotográfica dos aspectos de degradação ambiental resultantes dos eventos desencadeados nos primeiros meses do ano de 2010 e consultas a dados secundários e entrevistas com pesquisadores da Prefeitura Municipal.

\section{A IMPORTÂNCIA DA PAISAGEM NATURAL PARA O TURISMO}

A paisagem, onde em sentido amplo podemos definir como tudo que abarcamos com o olhar (GONTIJO e REGO, 2001), é um dos motores da atividade turística. E o turismo é uma das indústrias de maior peso econômico em nossos dias, e que se encontra em contínuo crescimento, com presença ampla e ativa de distintos fatores econômicos, relacionados à produção, circulação e consumo de bens e serviços, e tendo, portanto, investimentos das mais variadas naturezas (MENESES, 2002).

Segundo Bolson (2004) a paisagem não passou a existir após o nascimento do homem, ela já estava lá, porém, só quando o homem presta atenção na paisagem é que surge o seu conceito. A paisagem é o que se vê. $O$ real, o vivido, o sentido diferentemente para cada ser humano. Estes elaboram seleções pessoais, julgamentos de valor de acordo com a análise individual da percepção, e esta análise sofrem influências sociais, culturais, ambientais, emocionais conforme o tipo de uso da paisagem para cada pessoa.

As paisagens turísticas para Cruz (2002; p.110) remetendo a Luchiari (1998) ressalta que “... só existem em relação à sociedade. Elas não existem a priori, como um dado da natureza [...] é a ação social que dá sentido às paisagens, não o contrário", portanto, toda paisagem poder ser turística.

A imagem (induzida na paisagem) é um recurso para a economia do turismo porque é previamente definida por um valor social (CASTRO, 2002), podendo aí ser acrescido um valor cultural e mesmo histórico, onde o turismo utiliza destes valores 
para atribuir valor comercial as áreas turísticas. Estas áreas normalmente são preservadas, ou busca-se mantê-las sem interferência do homem, de modo que assim se atribua um valor, e onde se é pago para serem conhecidas (FONSECA, 2005).

Para Bertrand (2004; p.141) “... a paisagem não é a simples adição de elementos geográficos disparatados. É numa determinada porção do espaço, o resultado da combinação dinâmica, portanto instável, de elementos físicos, biológicos e antrópicos que, reagindo dialeticamente, uns sobre os outros, fazem da paisagem um conjunto único e indissociável, em perpétua evolução".

As paisagens estão carregadas de informação e retratam os lugares, como afirma Yázigi (2002), definindo assim a paisagem na perspectiva do turismo, onde está associada ao caráter de mercadoria, passível a ser consumida, valorizada e re-valorizada segundo o "modismo" da época, e onde Cruz (2002) acaba por complementar transcrevendo que para o turismo, é o valor estético da paisagem que está em pauta, e a estética da paisagem é ditada pelos padrões culturais de uma época.

\begin{abstract}
Cada pessoa tem um julgamento de valor diferente ao se deparar com uma determinada paisagem. Se um turista decide passar um final de semana em um hotel fazenda vai passear no campo em dia ensolarado, nas montanhas, provavelmente o que o chamará mais a atenção serão as diferentes colorações dos campos, as flores, o verde, a natureza e os animais. Já trabalhador rural, que cultiva a horta do hotel sua preocupação é com a limitação do espaço cultivado, a proteção contra as pragas e animais e se o clima estiver muito quente poderá comprometer seu trabalho. Para a família desse trabalhador, atravessar as montanhas a pé ou a cavalo para ir à escola, ou comprar algo na venda da cidade mais próxima é um incomodo. Já no ponto de vista de um motorista de caminhão que passa de fazenda em fazenda para apanhar a produção de leite e levá-la para a cooperativa na cidade, a paisagem pouco importa. Mas se o perguntarmos sobre o melhor trajeto e as condições da estrada certamente ele saberá informar com precisão. Ou seja, para cada observador a paisagem tem um sentido, seja de contemplação, utilitarista, estética e até mesmo indiferente (BOLSON, 2004. Disponível em: http://www.revistaturismo.com.br/artigos/paisagem.html)
\end{abstract}

Para a realização do turismo é necessário à apropriação dos lugares e o consumo de suas paisagens, promovendo assim relações e interações temporárias e mesmo permanentes, estabelecendo articulações entre o local turístico e o mundo através da inclusão dessas localidades em uma rede complexa e ampla que evolvem inúmeros atores, tais como a população local, governos e setores privados especializados nessa atividade. 
A paisagem é subjetiva e nesta concepção envolve para sua construção inúmeros fatores que estão diretamente relacionados com o modo de vida de cada indivíduo, onde este a percebe de maneira particular, acrescendo ou abstraindo elementos que lhe é pertinente ou não, tornando desta forma uma importante ferramenta dentro do turismo, pois esta pode ser manipulada de acordo com interesses mercadológicos, se tornando assim uma mercadoria turística.

Segundo Bolson (2004), o turista na verdade é um colecionador de paisagens. Meneses (2002; p.32) descreve que “... a paisagem, portanto, deve ser considerada como objeto de apropriação estética, sensorial". O primeiro contato do turista com o local visitado acontece através da visão da paisagem. Durante um tour o viajante se depara com uma diversidade enorme de paisagens, sejam naturais, culturais ou construídas, essas imagens é que permanecem no seu inconsciente e ao voltar para casa o turista se recorda dos lugares, das pessoas e das paisagens visitadas. Isso gera uma sensação de nostalgia além de acrescentar conhecimentos, e também leva as pessoas a cada vez mais buscarem o novo e neste sentido Boullón (2002) afirma que por mais diferente que seja o resultado de uma viagem é o acúmulo de experiências e lembranças dos lugares por que passou.

A relação do turista com o lugar visitado é sempre transitória, passageira, e na maioria das vezes, fugaz e superficial. A paisagem é a primeira instância do contato do turista com o lugar visitado e por isso está no centro da atratividade dos lugares para o turismo (CRUZ, 2002).

Os lugares ainda não degradados pelas atividades humanas e que possuem uma paisagem agora valorizada passam a ser objetos de consumo por parte de uma parcela da população que paga para poder desfrutar desses espaços, que se tornam cada vez mais raros. Essa raridade implica sua valorização, conforme uma das leis básicas do sistema econômico, e o consumo desses espaços passarem a ser desejado por parcelas cada vez maiores da população (FONSECA, 2005; p.29).

O crescimento da atividade turística traz consigo uma preocupação crescente, que é a "artificialização" dos lugares, o sentido de estranhamento da população local, a não-identidade ou mesmo uma perda de identidade, cria-se lugares vazios, não lugares (CARLOS, 1999).

A indústria do turismo transforma tudo o que toca em artificial, cria um mundo fictício e mistificado de lazer ilusório, onde o espaço se transforma em cenário, "espetáculo" para uma multidão amorfa [...]. Aqui o sujeito se entrega às manifestações desfrutando a própria alienação. Esse dois processos 
apontam para o fato de que ao se vender o espaço, produz-se a não-

identidade, e com isso, o não-lugar (CARLOS, 1999; p.26).

Bolson (2004; Disponível em: http://www.revistaturismo.com.br/artigos/paisagem.html) complementa: "O poder de atração de determinadas paisagens levam a sua reprodução construída artificialmente. Um bom exemplo disso são os grandes parques temáticos. Essas verdadeiras "ilhas da fantasia" simulam e reproduzem réplicas idênticas as originais e levam os visitantes a sentirem a sensação de que realmente presenciaram o original. Reproduzem não só as imagens, mas os costumes, a culinária, a raça, o cheiro. Esse mundo mágico, perfeito e divertido é um atrativo turístico bastante procurado".

A invasão dos espaços turísticos, principalmente localidades rurais ou litorâneas, faz com que o turista defronte seus hábitos, costumes, ou seja, sua cultura, com a cultura local ou do local, onde por meio desse "confronto" pode se notar a falta de preparo da maioria dessas comunidades no sentido de receber o turista sem absorver sua cultura, seus hábitos, perdendo assim a característica da comunidade, demonstrando muitas vezes a falta de diálogo entre estratégias de planejamento turístico e as ações sociais cotidianas pertinentes ao espaço turístico.

A preocupação com essa perda de identidade fez surgir e crescer uma nova segmentação no setor turístico, que é o turismo local, que possui ênfase no lugar, na comunidade, onde temos a preservação da cultura, do popular, trazendo o turista à realidade local, não a realidade do turista sendo levada a área visitada, o turista como um "novo" morador, não mais o invasor, permitindo dessa forma uma troca mútua de experiências, tornar o turismo uma atividade sócio-cultural, não mais apenas econômica.

\section{TURISMO E GEOGRAFIA}

O turismo é uma atividade complexa que se baseia no consumo do espaço geográfico como sugere Fonseca (2005), e possuí múltiplas relações econômicas, sociais, políticas e culturais que vem se difundindo de forma acelerada, movimentando capitais de enormes proporções e superando atividades tradicionais como a agricultura e a indústria. Guerra e Marçal (2006) complementam com a colocação que a atividade turística pode estar intimamente relacionada com o meio físico, em especial aquela vinculada à exploração das belezas naturais de uma determinada área, demonstrando, desta forma, o crescente interesse da Ciência Geográfica em seu estudo. 
A atividade do turismo sempre esteve atrelada à ideia de viagens, de deslocamento, surgindo oficialmente no século XVII, na Inglaterra, referindo a um tipo específico de viagem. Pela análise da origem do termo, que está ligada a palavra tour, que quer dizer volta e tem origem francesa, com seu equivalente no inglês turn ou no latim tornaire (BARRETO, 1995), está sempre ligada a ideia geral da ocorrência de um deslocamento pela busca do novo ou de se conhecer o novo.

Dentro deste contexto, pode-se articular a importância do turismo para a Ciência Geográfica a partir de dois pilares: um primeiro que está relacionado à necessidade de se conhecer as potencialidades dos lugares para a implantação desta atividade, procurando vincular as benesses para a área que venha trazer neste segmento da economia; e um segundo que se refere à busca do entendimento da "fragilidade" dos lugares para que os mesmos não sejam afetados negativamente, que por muitas vezes, tem trazido alterações ambientais degradantes e/ou alterações culturais ou perda de identidade cultural para comunidades locais.

Por esta razão, Rodrigues (1996) define a atividade turística como um fenômeno econômico, político, social e cultural dos mais expressivos das sociedades ditas pósindustriais, onde movimenta, em nível mundial, um enorme volume de pessoas e de capital, inscrevendo-se materialmente de forma cada vez mais significativa ao criar e recriar espaços diversificados.

Cabe ressaltar ainda que essa atividade se adapta bem ao contexto de valorizar as "belezas paradisíacas" produzidas pela natureza, especialmente em regiões pouco habitadas e de difícil acesso (OLIVEIRA, 2001) e, portanto, o turismo pode ser considerado como uma das formas de lazer que se distingue das demais pelo fato do indivíduo ter que se deslocar de seu local de cotidiano para praticá-lo. Fazer turismo implica uma ruptura com o cotidiano uma vez que o indivíduo tem necessariamente que viajar para que possa ser considerado turista (FONSECA, 2005). Sendo a atividade turística considerada uma quebra do cotidiano e o "consumo" do espaço, este deve possuir atrativos para tal, sendo a paisagem de grande importância, pois normalmente esses deslocamentos vêem em busca do novo, em busca muitas vezes das paisagens ditas exóticas.

Segundo Molina (2001) o turismo se relaciona com as necessidades fundamentais do ser humano, como por exemplo, a educação, e nesse contexto, com o 
aprendizado e identificação com outras culturas e grupos étnicos e a diversidade de recursos naturais. $\mathrm{O}$ autor afirma ainda que o turismo proporcionar experiências emotivas e cognitivas de grande riqueza e valor, já que oferece aos indivíduos a possibilidade interação com o meio que o cerca.

Coriolano (2003) disserta que os pressupostos básicos para a aplicação do turismo em um país ou região, passam pela construção do real (como espaço da oferta turística) e pela construção do espaço virtual (objeto do imaginário formado de imagens, sonhos e mitos de um povo, grupo ou indivíduo) demonstrando que a construção do imaginário turístico está relacionado com a (re)construção da paisagem do local a qual se pretende visitar, sendo que estas representações ocorrem a partir do momento da intenção da viagem, onde vai sendo desvelado na realização da viagem.

Esta mesma autora demonstra ainda que dentro desta concepção do turismo, duas realidades distintas são formadas, a primeira situando-se no plano do real e revelando os lugares turísticos cheios de potencialidades e fortalezas, mas também com fragilidades e ameaças e a segunda onde se situa o plano da imagem, do imaginário e do simbólico, revelando as representações que se fazem desses lugares e enfocando questões virtuais que nem sempre coincidem com o real.

\section{TURISMO E FRAGILIDADE AMBIENTAL EM ANGRA DOS REIS}

A paisagem, principalmente a vinculada a elementos naturais é um dos maiores motores do turismo em todos os níveis (nacional e mundial) e o município de Angra dos Reis não foge a essa regra, visto que seus principais atrativos consistem em seus elementos naturais, sendo os mais expressivos as praias, ilhas e também a "interação" íntima da serra com o mar, que é parte essencial neste local. Portanto, é inegável que a configuração geomorfológica que tanto atraí o turista para Angra dos Reis também se mostra frágil e mesmo "perigosa", haja vista os aspectos evolutivos naturais da área, como os processos geomorfológicos ocorridos nos anos de 2002 e 2010 que se tornaram um transtorno para o município.

O planejamento turístico se faz, portanto, necessário principalmente em áreas que apresentam uma fragilidade ambiental elevada, devendo ser levado em consideração não só a preservação do local, mas também a localização de pontos fixos, no que se refere aos pontos turísticos, abrangendo pousadas, hotéis, áreas de lazer em 
geral como clubes, bares, entre outros, e até mesmo as residências de moradores, que de forma direta ou indireta são responsáveis pela movimentação do turismo em seu local de moradia.

O turista deve poder usufruir de todos os atrativos disponíveis, mas em segurança para que o ciclo do turismo não seja interrompido, e cidades que possuem boa parte de sua arrecadação, como no caso de Angra dos Reis, possam sempre contar com esta fonte de renda. É importante ressaltar que o turismo praticado neste município é quase em sua totalidade vinculado a elementos da natureza e esta não pode vir a se tornar elemento de repulsão turística, portanto, ressalta-se novamente a importância do entendimento e compreensão da fragilidade local e da busca de mitigação dos impactos negativos que possam vir a ser desencadeados na área.

A exuberante paisagem da Costa Verde (RJ) e as questões de "instabilidade" ambiental

A região denominada Costa Vede (Figura 1) é composta por mais de 2.000 praias e 350 ilhas, protegidas das intempéries do mar aberto pela barreira formada pela Restinga de Marambaia. As cores da água nessa parte do litoral fluminense, que variam em distintas tonalidades de verde, constituem-se atrativo especial e ideal para a prática de qualquer modalidade de esporte aquático. Esse trecho da costa brasileira reúne excelentes condições para a navegação desportiva e concentra aproximadamente $90 \%$ da frota de embarcações de lazer do país (MINISTÉRIO DE RELAÇÕES EXTERIORES - Disponível em: www.dc.mre.gov.br/imagens-e-textos/revista1mat9.pdf). É grande o número de praias desertas com águas calmas e transparentes e areias brancas, que só se tem acesso pelo mar; e correntes marítimas generosas que trazem grande quantidade de lagostas e várias espécies de peixes às redes dos pescadores. Estes se encarregam de narrar aos visitantes as lendas da região, que remontam aos tempos em que a cidade de Angra dos Reis era esconderijo de corsários.

Prolongando-se a partir de Angra dos Reis se tem um dos municípios mais antigos da região que é Parati, tendo sua ocupação ainda no século XVI, em decorrência da abertura de caminhos que ligassem as Províncias de São Paulo e Minas Gerais à do Rio de Janeiro. Fazendeiros e comerciantes foram aos poucos se estabelecendo na região, gerando significativo dinamismo econômico na época do império. Em 1844, a Vila de Parati foi elevada à categoria de cidade. Nesse período, Parati, juntamente com 
Angra dos Reis e Mangaratiba, eram importantes núcleos para o escoamento da produção de café do Vale do Paraíba. E, em fins do século XIX, inicia-se o declínio da região de Parati, resultado de inúmeros fatores, como: a abolição da escravatura, em 1888, que provocou o êxodo rural dos libertos; a mudança da rota da produção cafeeira, que passava a ser transportada por via férrea, não mais utilizando as estradas que tinham em Parati um dos pontos de desembarque; e a obstrução dos rios, resultando em surtos epidêmicos, como o da malária. E no início do século $\mathrm{XX}$, a população local não passava de 10.000 habitantes (MINISTÉRIO DE RELAÇÕES EXTERIORES Disponível em: www.mre.gov.br/dc/textos/revista1-mat9.pdf).

Especificamente no município de Angra dos Reis, localizado entre as coordenadas geográficas $23^{\circ} 00^{\prime} 24^{\prime \prime} \mathrm{S}$ e $44^{\circ} 19^{\prime} 05^{\prime \prime} \mathrm{W}$, a ocupação urbana se distribui ao longo da BR-101 (que corta o município longitudinalmente e serve de ligação entre os núcleos urbanos existentes), concentrando-se nas reduzidas planícies costeiras e avançando em direção as encostas. Nestes segmentos do relevo a ocupação ultrapassa a altitude de 60m, que foi estabelecida pelo Plano Diretor Municipal (Lei $\mathrm{n}^{\circ}$ 162/91) como cota limite para edificações (FRANCISCO e CARVALHO, 2004), e gera inúmeros problemas ambientais ao município pelo ritmo acelerado de ocupação, sem políticas de controle e manejo do uso do solo. Esta pequena faixa litorânea que se entrelaça com a escarpa da Serra do Mar, e possui aproximadamente $819 \mathrm{Km}^{2}$ de extensão e está a seis metros de altitude ao nível do mar, possui atualmente uma população de aproximadamente 150 mil habitantes e é um local único no estado do Rio de Janeiro.

Por fim, ressalta-se que a denominação Costa Verde é bastante conhecida e utilizada por diversos órgãos de turismo do estado do Rio de Janeiro, tais como: a) a proposta da Companhia de Turismo - RJ (www.turismo-rj.gov.br), que é um órgão privado e tem como objetivo a divulgação de áreas com potencial turístico para o estado; b) o zoneamento proposto pelo Instituto Virtual de Turismo (IVT), organizado pela COPPE-UFRJ (www.ivt-rj.net), que objetiva promover o desenvolvimento da interdisciplinaridade e do estudo do Turismo; c) da Associação Brasileira da Indústria de Hotéis - ABIH (www.abih.com.br), que é uma entidade que congrega as empresas de hospedagem com sede e estabelecimentos no estado; e d) o zoneamento do Instituto Brasileiro de Geografia e Estatística - IBGE (www.ibge.gov.br). Todas estas propostas 
ressaltam as características do ambiente Serra e Mar como de destaque para atrativo dos turistas e, além destas, a tipologia proposta para o estado, elaborada por Ribeiro (2003), apresenta um maior detalhamento das unidades turísticas por relacionar tanto aspectos físico-ambientais como as funções turísticas e destaca a área como "função/tipo litorânea" e subdivida ainda em "praia-naútica e "praia-naútica/histórica", onde no primeiro subtipo predominariam atividades turísticas que conjugam o trinômio sol-céumar com diversas modalidades naúticas e o segundo conjugariam as atividades de praia e naútica, bem como apresentariam fixos históricos que marcam suas paisagens, através de casarios coloniais, igrejas, fortes, entre outros. Para finalizar, a proposta apresentada por Soares e Silva (2009) classifica a área como subunidade turística de Praias e Escarpas Serranas (Figura 1), sendo os critérios utilizados voltados à valorização das características geomorfológicas e, na qual, foram utilizados o mapa geomorfológico do Rio de Janeiro elaborado em escala de detalhe por Silva (2002). Esta subunidade turística, constituída pelos municípios de Mangaratiba, Angra dos Reis e Paraty, foi morfologicamente caracterizada pela ocorrência de praias e planícies estreitas constituídas de sedimentos quaternários, que se encontram espremidas entre a escarpa da serra da Bocaina e o oceano, e em que há a presença de manguezais ao longo dos principais canais fluviais que desembocam na Baía de Ilha Grande.

Por se tratar de uma área que possui a morfologia de serras, o município possui, em sua maioria, elevadas declividades e uma concentração significativa de depósitos de encosta, composto essencialmente por depósitos de tálus entremeados a colúvios, e que se traduzem como aspecto de fragilidade e, portanto, como importantes fatores condicionantes para a ocorrência de movimentos gravitacionais de massa. Como coloca Fernandes e Amaral (2006; p.159-160):

\footnotetext{
Em geral, uma das principais características desses materiais é a grande heterogeneidade interna, a qual é resultante direta da descontinuidade espacial dos processos formadores desses depósitos. Os depósitos de tálus são geralmente, mal selecionados e se formaram em segmentos mais basais das encostas, tal como a base de paredões rochosos, já os colúvios são, em geral, melhor selecionados e recobrem muitas encostas de ambientes de menor energia.
}

Esses depósitos de encosta no município se encontram muitas vezes sobre rocha sã, o que facilita a ocorrência de deslizamentos de terra por conta de fatores como: descontinuidades das propriedades físicas entre os materiais, que associados a eventos 
chuvosos elevados, como os ocorridos em dezembro de 2002 e no início de 2010 no município de Angra dos Reis, correspondem a aspectos inerentes ao desencadeamento destes processos de encosta, ou seja, demonstram a enorme fragilidade ambiental das características naturais locais. No mapeamento apresentado pela figura 1 pode-se perceber que Angra dos Reis possui apenas 7,45\% de áreas planas e 73,26\% área serrana, ou seja, áreas que pelo aspecto relacionada às declividades do terreno seriam naturalmente instáveis. Desta forma, a natureza que é a maior aliada do turismo no município mostra-se também muito frágil, constituindo um sério obstáculo para o bom funcionamento da economia local.

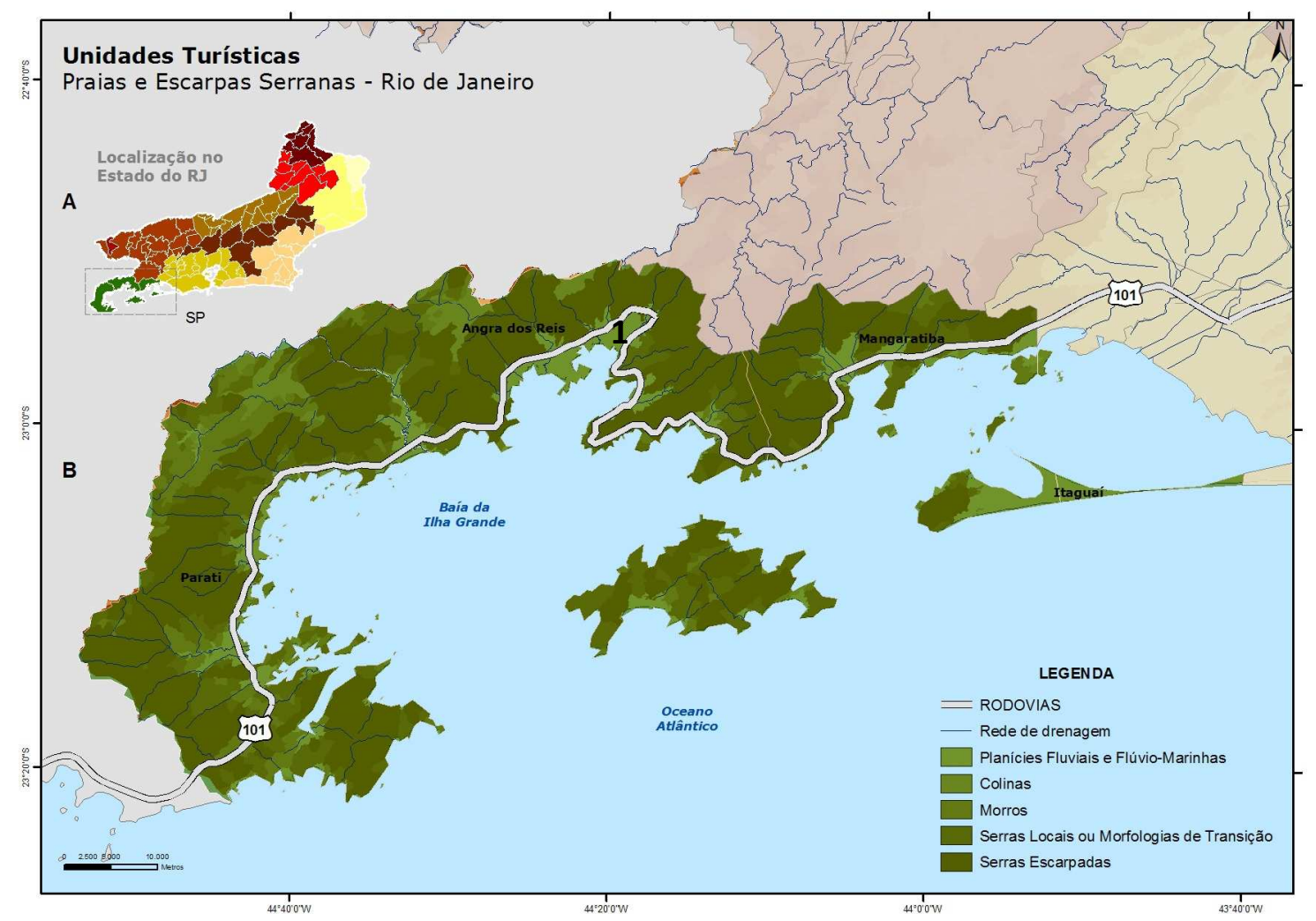

Figura 1: Localização da Área de Estudo e a distribuição de feições geomorfológicas: A - Mapa de unidades turísticas do Rio de Janeiro e B - Unidade Turística Praias e Escarpas Serranas - Fonte de informações: Silva (2002) e Soares e Silva (2009); 1 Localização dos bairros de Areal, Japuíba e Grande Belém na planície flúvio-marinha do rio Japuíba. 
A calamidade de Angra dos Reis em eventos chuvosos nos anos de 2002 e 2010 e os impactos sobre o patrimônio natural

Os processos de movimentos gravitacionais de massa e os respectivos aspectos de calamidade vivida pelo município de Angra dos Reis nos dois anos fatídicos (2002 e 2010) serão aqui exemplificados como eventos que alteraram substancialmente a atividade turística e, por consequência, desestabilizou, em parte, a economia local.

Mesmo que a população e, principalmente, a imprensa em geral associar à ocorrência de movimentos gravitacionais de massa à ocupação humana, temos com frequência a observação de eventos relacionados a causas estritamente naturais, não só na área em estudo como em todo sudeste brasileiro, em especial nas encostas da Serra do Mar.

O evento ocorrido em 09 de dezembro de 2002 é um exemplo onde as encostas do segmento à montante da bacia de drenagem do rio Japuíba, em que se localizam os bairros de Areal, Japuíba e Grande Belém, levou à destruição da linha férrea, de várias construções e o óbito de cerca de quinze pessoas em Areal. Estes episódios erosivos foram resultado de eventos pluviométricos extremos que afetou, principalmente, os trechos a montante da bacia e desencadeou em uma corrida de detritos que chegou a atingir à ocupação localizada no segmento mais a jusante da referida bacia. Fato interessante é que a maior parte dos deslizamentos ocorreu em área com floresta preservada, demonstrando que a vegetação não impede à ocorrência de tais processos, mas que outros fatores de ordem geológica, geomorfológica e/ou climática assumem papel fundamental, levando a uma diminuição da estabilidade das encostas e resultando na ruptura das condições de 'equilíbrio'. Embora este movimento gravitacional de massa não tenha sido como os ocorridos ao longo da BR-101, seu mecanismo é também bastante representativo para o município.

Segundo a Defesa Civil do município (www.angra.rj.gov.br/defesacivil), o índice pluviométrico foi de $275 \mathrm{~mm}$ apenas neste dia (09/12) e corresponderia ao total esperado para todo mês de dezembro, levando a situações inesperadas e alarmantes para os bairros de Areal, Japuíba e Grande Belém como: quarenta vítimas fatais, mais de 100 feridos e, por volta, de 2.500 pessoas desabrigadas. Além disto, após vistorias realizadas por técnicos da Prefeitura Municipal houve ainda a interdição de 600 residências, bem como em outros estabelecimentos. 
Já os eventos de movimentos gravitacionais de massa registrados na madrugada do dia $1^{\circ}$ de janeiro de 2010 , época de grande movimentação turística no município, tiveram efeito de dimensões catastróficas. Este evento foi resultante de uma combinação de elevado índice pluviométrico concentrado, chovendo o equivalente a $417 \mathrm{~mm} \mathrm{em}$ apenas três dias, com as condições de susceptibilidades locais. Houve dois eventos de movimentos gravitacionais de massa de dimensões significativas: um localizado na enseada de Bananal, Ilha Grande - definido pelo Prof. Nelson Ferreira Fernandes (2010; Comunicação verbal) como do tipo escorregamento raso, também denominado como escorregamento translacional, onde acompanha, de modo geral, descontinuidades mecânicas e/ou hidrológicas existentes no interior do pacote de material existente na encosta. Este tipo de processo geralmente são compridos e rasos, onde o plano de ruptura encontra-se, na maioria das vezes, em profundidades que variam entre 0,5 e 5,0 (FERNANDES e AMARAL, 2006). Além disso, na enseada de Bananal há a presença de inúmeras cicatrizes de antigos eventos, que demonstram a recorrência de movimentações anteriores, e que poderiam e podem, por sua vez, servir de indicativo para geração de possíveis eventos; além de também ser constatada a presença notória de fraturas de alívio de tensão. Outro evento registrado ocorreu no Morro da Carioca (Figura 2), localizado na área continental de Angra dos Reis e nos arredores do Centro da cidade, também classificado por este mesmo professor como sendo um escorregamento raso, e onde também pode se observar a existência de antigas cicatrizes que poderiam ter servido como indicativo das condições de fragilidade físicoambientais locais.

Segundo dados obtidos pela Defesa Civil municipal, dos 118 bairros existentes no município, sessenta e um foram atingidos por algum tipo de ocorrência, além de movimentos gravitacionais de massa, quedas de árvores, muros, postes, casas e muitos alagamentos, e diversos trechos da BR-101 foram interditados por causa da queda de barreiras, totalizando trinta e sete pontos. O número de vítimas atingiu um total de cinquenta e três pessoas, entre turistas e moradores locais. Neste período, moradores da localidade conhecida como 'Estrada do Contorno' ficaram totalmente isolados, sem nenhum tipo de comunicação e energia elétrica, e o acesso só se fazia pelo mar através de lanchas particulares ou de embarcações disponibilizadas pela Prefeitura. Ainda foram registrados pela Defesa Civil mais de 5.500 pessoas desabrigadas, 1.200 interdições, 
dentre outras ocorrências, sendo necessário utilizar cinco escolas municipais, uma estadual e uma Fundação como abrigo durante dois meses. Todos estes aspectos fizeram com que a Prefeitura Municipal decretasse estado de calamidade pública.

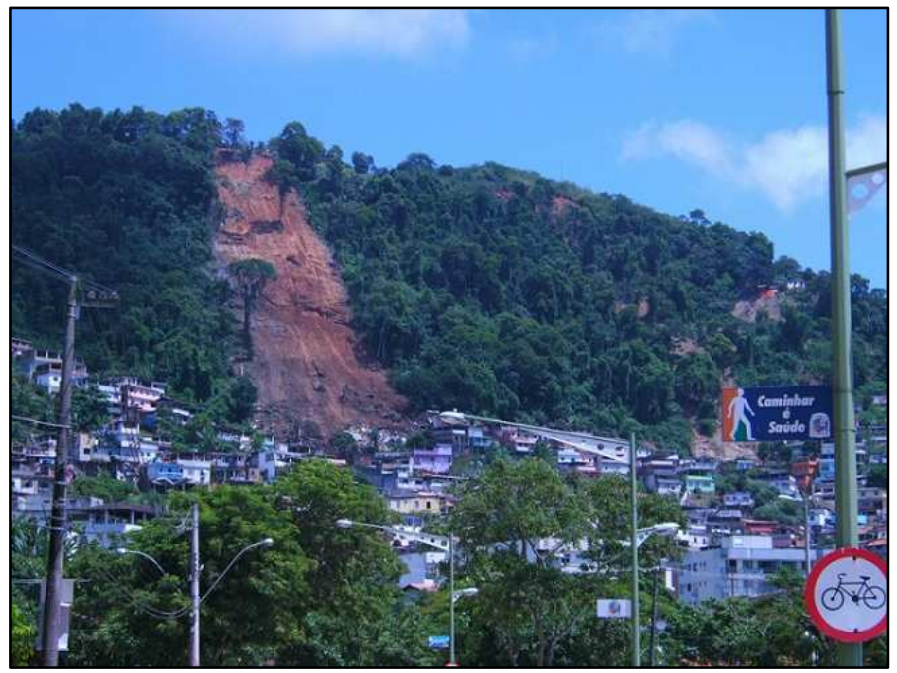

Figura 2: Foto panorâmica do movimento gravitacional de massa ocorrido na localidade Morro da Carioca no centro do município de Angra dos Reis em 31 de dezembro de 2010. Fotografia: E.A.L. Pocidonio (Janeiro/2010).

O município ainda se deparou com pontos de movimentos gravitacionais de massa, principalmente ao longo da rodovia BR-101, que permaneceu fechada por dois dias no mês de abril de 2010, por conta de novas quedas de blocos ocorridas na altura de Conceição de Jacareí, distrito que faz divisa entre os municípios de Angra dos Reis e Mangaratiba. Nas incursões de campo foram verificados inúmeros pontos de deslizamentos, ocasionados por fatores distintos ou por uma associação de fatores tais como: fraturas de alívio de tensão, descontinuidade hidráulica, presença de raízes extensas, entre outras características. Todos estes aspectos associados as chuvas fortes e concentradas favoreceram o desencadeamento destes processos nas encostas.

A setorização turística de Angra dos Reis: os "Corredores Turísticos”": breve descrição

Em realidade, o turismo no município de Angra dos Reis ganhou grande dinamismo a partir da construção da rodovia BR-101 na década de 1970, tendo-se nesta atividade uma forma de implementar a receita local, que antes do boom econômico causado pelos projetos federais, tais como o Estaleiro Verolme (atual Brasfels), Usinas Nucleares e o Terminal da PETROBRAS, tinha sua economia baseada no setor agrícola 
e pesqueiro e que após estas implementações, houve um crescimento na área por prestação de serviços, e dentre elas, atividades que visam atender ao turismo.

Assim sendo, a Prefeitura Municipal de Angra dos Reis realizou na década de 1990 um zoneamento turístico denominado de Corredores Turísticos, que são subdivididos pela posição geográfica que ocupam: Corredor Turístico do Centro, Corredor Turístico da Estrada do Contorno, Corredor Turístico da Ponta Leste, Corredor Turístico Ponta Sul e Corredor da Ilha Grande (Figura 3).

\footnotetext{
Para Ignarra (2003: p. 20), corredores turísticos são “...vias de inter-relação entre várias áreas turísticas, ou entre centros históricos, ou entre portões de entrada e os centros turísticos. O conceito de corredor turístico não é unicamente uma via de acesso a uma determinada área, mas sim de uma faixa de território que serve de ligação entre vários elementos turísticos e que se constitui ela própria em um atrativo".
}

Neste sentido, o autor demonstra a ideia do corredor como uma ligação física entre os vários elementos ou potenciais turísticos de uma localidade, permitindo desta forma um aprimoramento do atendimento ao público, ou seja, ao turista, uma valorização do local turístico, onde teremos uma re(valorização) de áreas e ainda a possibilidade de melhoria da comunidade local. A implementação de um corredor turístico pode vir a se tornar uma importante oportunidade de geração de divisas para as comunidades ou municípios englobados. Exemplificando este conceito, o autor coloca como exemplo uma rodovia litorânea, podendo esta ter utilidade para ligar duas cidades costeiras, além de afirmar que a própria estrada pode se constituir um atrativo turístico, por conta de sua beleza cênica.

Este zoneamento foi elaborado pelo SEBRAE junto a outras entidades envolvidas no ramo, tais como a Associação de Turismo da Costa Verde (ATCV) e um fórum de empresários, além da parceria com a Prefeitura Municipal e não teve nenhuma regulamentação até os dias de hoje (Sra. Rita Carreira - Agente de Informações Turísticas da Gerência de Projetos, Comercialização e Marketing da Prefeitura Municipal de Angra dos Reis; Comunicação verbal). E teve também como finalidade a criação de um plano de marketing para ordenar o município e criar argumentos para a venda imobiliária segundo diferentes características de cada corredor.

Os critérios para a realização desta setorização se relacionam aos principais atrativos turísticos existentes que podem ser observados pela figura 3, onde são enfatizados os atrativos Histórico/Culturais e Naturais em cada setor discriminado. 
Cada Corredor possui sua particularidade e a partir da realização dos trabalhos de campo, busca em sites especializados na temática turística, tendo como fonte-base o site da Fundação de Turismo/TurisAngra (www.turisangra.rj.gov.br) e aplicação de metodologia proposta e adaptada pela ABG Engenharia e Meio Ambiente Ltda. (2008) foram levantados pontos e atrativos turísticos específicos de cada Corredor da parte continental do município.

No Corredor Turístico do Centro p.ex., dezenove atrativos foram identificados, onde apenas um se insere na categoria atrativo natural, a Praia do Anil, que mesmo sendo imprópria para banho se encontra em uma posição privilegiada do município, e é palco da maioria dos grandes eventos da cidade, tais como o já consagrado FITA (Festival Internacional de Teatro), Expo Cristã, Costa Verde Negócios, o Reveillon, além de nela está localizado o Centro de Informações Turísticas (CIT) da TurisAngra. Os demais atrativos estão segmentos entre casarios, praças, monumentos e igrejas, onde podemos citar a Biblioteca Municipal, Casa de Cultura, Casa Laranjeiras e Mercado do Peixe, ambos localizados na Praça Zumbi dos Palmares, igrejas como a Matriz Nossa Senhora da Conceição, N. S. do Carmo, N. S. da Lapa ou Boa Morte, que abriga um importante museu de arte sacra, além de praças, onde se destaca a Praça Amaral Peixoto, mais conhecida como Praça do Porto, que é a mais movimentada e que exerce a função de ponto de encontro nas noites da cidade. É nesta praça onde ocorrem eventos tais como "Noites Angrenses", que conta com uma gama diversificada de atrações, tais como apresentações teatrais e shows com artistas locais e convidados.

O Corredor Turístico do Contorno possui um total de quatorze atrativos levantados, sendo apenas dois inseridos na categoria histórico/cultural e compondo um dos principais em grau de atratividade, que são respectivamente Colégio Naval e Igreja do Bonfim. Os atrativos naturais são compostos por praias que vão desde movimentas, com presença de quiosques, bares e restaurantes, como a Praia Grande, a praias praticamente desertas e de difícil acesso com é o caso da Praia da Gruta. Nesse Corredor se encontram ainda os resorts mais caros e procurados do município, tais como o Vila Galé, localizado na praia do Tanguá e Angra Inn, na Praia Grande. 


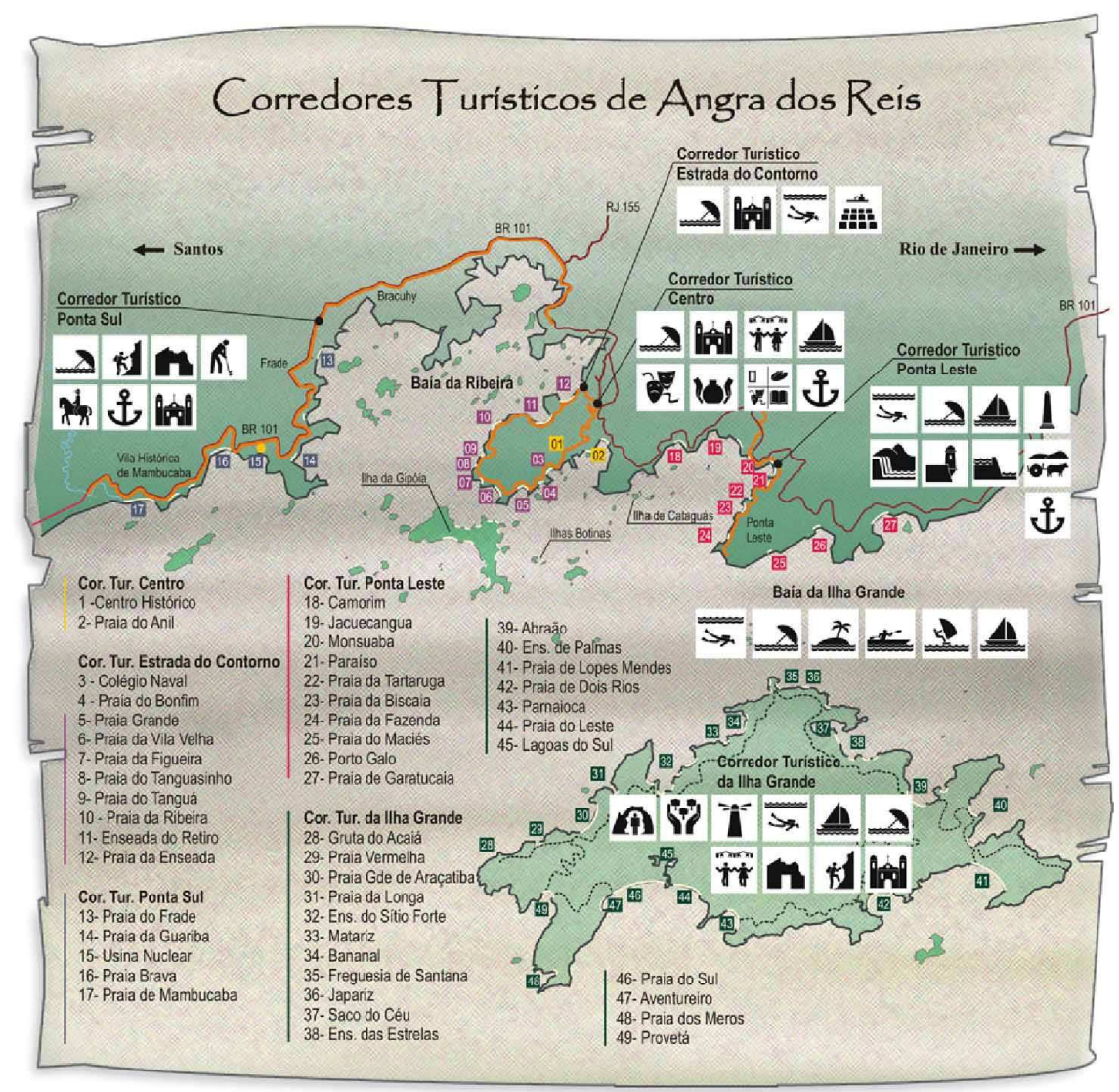

Figura 3: Corredores Turísticos de Angra dos Reis. Fonte: Prefeitura de Angra dos Reis (Disponível em: www.angra.rj.gov.br).

Já o denominado Corredor Ponta Sul possui belas praias, tais como a Praia Secreta, Praia Brava, Guariba e Mambucaba, esta tem como principal atratividade a Vila Histórica, que mescla belezas naturais com histórico-culturais se tornando importante motivador turístico. Outros atrativos são as cachoeiras localizadas em bairros como Ariró, Zungú e Bracuhy, este possui uma reserva indígena que ainda preserva boa parte de sua cultura, possuindo até mesmo uma escola indígena para os moradores dessa reserva, a Escola Estadual Guarani Karai Kuery Renda, localizada na aldeia Sapukai e o belo vale do rio Mambucaba, que é o mais extenso do município. Ressalta-se ainda como atrativo as Usinas Nucleares Angra I, II e III que se encontram também nesse Corredor Turístico. E de um total de doze atrativos levantados, apenas dois se enquadram na categoria histórico-cultural.

O Corredor Ponta Leste não foge a regra do Corredor Ponta Sul e possui nas praias seu principal atrativo, sendo a Praia das Éguas, Biscaia e Maciéis as mais conhecidas. Os Canhões do Forte do Leme e o Monumento aos Náufragos do Aquidabã 
são pontos de atratividade, além de inúmeras cachoeiras no bairro da Caputera e das praias da Tartaruga, Paraíso, da Fazenda, Garatucaia. Neste corredor foram levantados vinte e dois atrativos turísticos, sendo desde total, dezenove naturais e apenas três na categoria de histórico-culturais.

A Ilha Grande, que se constitui por um único Corredor Turístico, possui uma área de 192 km², com 106 praias, inúmeras cachoeiras e muitas áreas para realização de trilhas, que vão desde o nível mais leve - que são para as praias próximas a área central, praia do Abraão, e que é a área mais bem equipada da ilha, com existência de mercadinhos, lan house, posto médico e um grande número de estabelecimentos de hospedagem -, a percursos mais pesados, como as trilhas pra o Pico do Papagaio e Dois Rios, onde se localiza as ruínas do antigo presídio. Entre os locais mais conhecidos deste 'Corredor' estão às praias de Lopes Mendes, Aventureiro, Parnaioca, Saco do Céu, Abraão e Dois Rios.

Ressaltando que a metodologia de hierarquização turística foi aplicada apenas nos corredores da parte continental do município, sendo o Corredor Ilha Grande avaliado a partir de pesquisa em sites especializados na temática turística e que pode ser verificado a partir da descrição dos corredores, os elementos naturais formam a maior parte dos atrativos, tornando a eventos naturais, tais como chuvas de grande intensidades e MGMs interferem de forma significativa no funcionamento da prática turística municipal, sendo visualizado desta forma a necessidade de melhor compreensão desde segmento econômico assim como a compreensão de processos evolutivos locais.

\section{Os corredores turísticos em Angra dos Reis e a desestruturação local}

Os trabalhos de campo realizados nos meses de janeiro a maio de 2010 consistiram na identificação das características discriminadas em cada setor proposto por este zoneamento para a parte continental, sendo avaliados tanto os atrativos quanto os problemas de cada corredor em específico e, principalmente, aqueles voltados para os processos de encosta que cada setor destes foi afetado nos primeiros meses de 2010.

Observou-se que o Corredor Turístico do Contorno foi o mais afetado pelas chuvas de 2010. Este corredor é cortado por uma única e estreita estrada de acesso, que possui condições de tráfego bastante complicadas em situação de dias normais, onde são 
agravados em alguns períodos tais como feriados prolongados e durante todo o verão, tendo esta situação ficado insustentável neste período do ano de 2010. Diversos trechos sofreram interdições, deixando moradores de bairros localizados ao longo deste corredor isolados por mais de 72 horas, só sendo possível o deslocamento por meio de embarcações disponibilizadas pela Prefeitura Municipal em horários pré-definidos, e que transportaram tanto moradores, proprietários de hotéis e pousadas, quanto turistas. Bairros como Bonfim, que teve casas destruídas, Vila Velha e condomínios como os localizados na praia da Figueira são exemplos de áreas afetadas neste setor (Figura 4). Hotéis, resorts e pousadas tiveram que realizar esquemas especiais durante o início de janeiro de 2010, assim como durante todo o período do verão de 2010, a fim de minimizar os prejuízos, tais como: disponibilidade de embarcações para hóspedes e funcionários, descontos em suas tarifas e propagandas "positivas" sobre a área. No entanto, marcas dos deslizamentos ainda são visíveis até os dias atuais, sejam por meio de obras de contenção ou pela cicatrizes dos movimentos gravitacionais ainda presentes nas encostas.
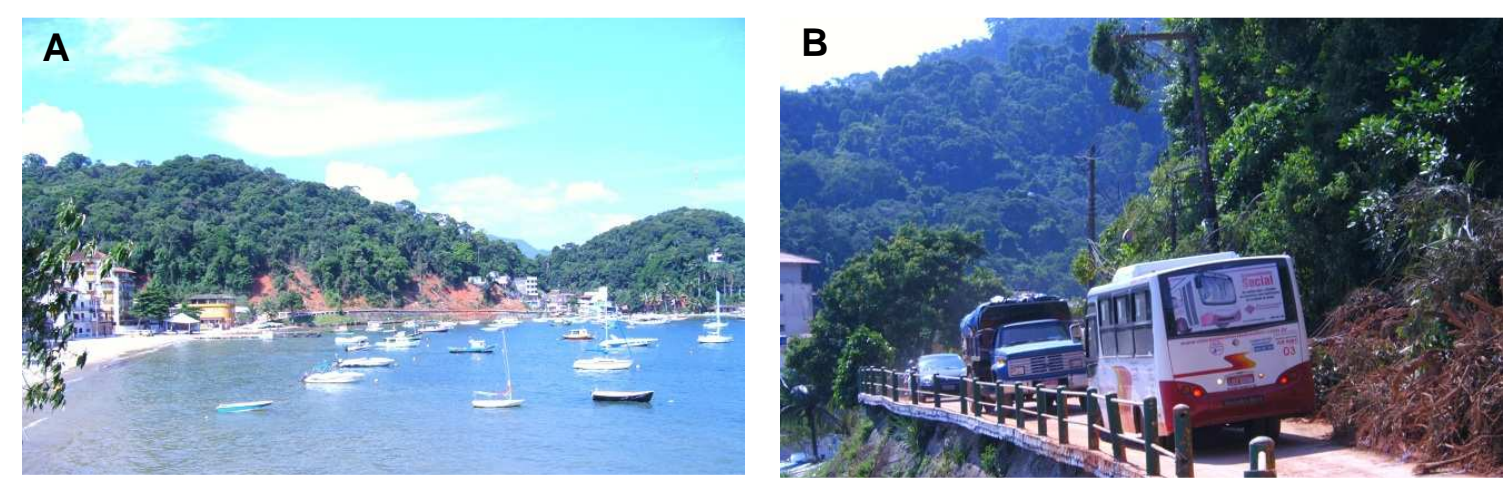

Figura 4: Deslizamentos no Corredor Turístico Estrada do Contorno (A) que deixou o tráfego em meia pista por inúmeras semanas (B). Fotos: E.A.L. Pocidonio (Janeiro/2010).

O Corredor do Centro foi afetado indiretamente pelos processos de encosta ocorridos nas comunidades que circundam o Centro do município, tais como aqueles nos morros Glória (I e II) e Perez, assim como no morro do Carioca, onde se registrou óbitos de moradores locais, como supracitado, além de alagamentos e concentração de detritos nas ruas ocasionado pelos movimentos gravitacionais de massa de encostas próximas. No Corredor Ponta Sul as consequências do intenso regime pluviométrico foram bem próximos ao do Corredor Centro, sendo que pelo fato de ser diretamente cortado longitudinalmente pela BR-101, teve interrupções de tráfego por conta dos 
MGMs ao longo da via. Nesta área, as ocorrências mais expressivas foram os inúmeros alagamentos nos bairros Parque Mambucaba (antigo Perequê) e Santa Rita (I e II), que já possuem um histórico desses acontecimentos que estão associados ao aumento da vazão fluvial e/ou a variações da maré (Salgado et al., 2007). E ao longo do Corredor Ponta Leste, também ocorreram processos de encosta em início de janeiro, no entanto os eventos mais graves foram desencadeados em momentos posteriores, mais especificamente no mês de abril em que ocasionou o fechamento da BR-101 por inúmeras vezes, na altura do condomínio Porto Galo.

\section{CONCLUSÃO}

Ao longo deste trabalho pode-se observar que situações passadas de forte desestruturação local, bem como os eventos de 2010, demonstram a necessidade urgente de estudos detalhados que permitam o reconhecimento tanto da fragilidade da morfologia local, quanto da susceptibilidade de características geológicogeomorfológicas e pedológicas dos terrenos, em busca da minimização dos aspectos de degradação ambiental frente à ocorrência de eventos chuvosos extremos.

Foi observado que no intervalo de oito anos, entre 2002 e 2010, processos de encosta ocorreram sem que os dirigentes locais dessem a devida atenção e a implementação de procedimentos que evitassem tais catástrofes. Desta forma, estes episódios acabam sendo um fator de repulsão turística, e que desestabiliza a economia local que tem no turismo um dos principais fatores de arrecadação de divisas. Torna-se, portanto, necessário respeitar e conhecer as reais condições de fragilidade ambiental da área para que se possam realizar medidas para um planejamento consciente e adequado de uso do solo na área.

Em relação aos tipos de movimentos gravitacionais de massa com potencialidade de ocorrência na área, existem tanto os do tipo corridas de massa (ou de detritos) - em locais de elevada declividade e topografia convergente, os movimentos de massa que se iniciam nos segmentos superiores das encostas se propagam em direção ao fundo dos vales, assumindo velocidade e características de corridas de detritos. Tais processos possuem um elevado poder de destruição, carregando 'tudo que esteja a sua frente', com alto poder de destruição nos segmentos localizados na base das encostas e até mesmo mais à jusante das bacias e sub-bacias de drenagem e, consequentemente, 
desestabilizando os processos produtivos locais. Também são notórios os do tipo escorregamentos rasos em setores das encostas que possuem pequena espessura de solo sobre rochas impermeáveis, e que ocorrem nos mais diversos pontos do município, desde ao longo das estradas e de ocupações que cortam as encostas, quanto em áreas coberta pela vegetação.

Estudos que procurem conhecer melhor a fragilidade local e seus eventuais riscos se mostram necessários para o município, visto que muitos aspectos desta "fragilidade natural" ainda precisam ser compreendidos no intuito de evitar ou minimizar novos eventos catastróficos de magnitude tão elevadas como foram estes eventos aqui trazidos. A paisagem nesta área é símbolo de atratividade, por estar carregada de belas informações e que retratam muito bem este lugar, como se refere Yázigi (2002) ao mencionar a importância da paisagem para o turismo, e deve, portanto procurar afastar os aspectos duvidosos ao turista que tanto deseja conhecer uma área tão bela e constituída de inúmeros atrativos. Além deste aspecto a população local tem o direito, e também o dever, de contribuir através do conhecimento e conscientização das fragilidades ambientais do município, que deve ser encaminhada por uma política séria e informativa da Prefeitura Municipal.

\section{REFERÊNCIAS BIBLIOGRÁFICAS}

ABG Engenharia e Meio Ambiente Ltda. Projeto básico ambiental UHE São José Programa de apoio ao desenvolvimento turístico. Relatório de levantamento dos produtos turísticos do entorno da Usina Hidrelétrica de São José (UHE São José) - rio Ijuí, municípios de Salvados das Missões e Rolador - RS. Porto Alegre: 2008.

ASSOCIAÇÃO BRASILEIRA DE INDÚSTRIA DE HÓTEIS - ABID. Disponível em: www.abih.com.br. Acesso em: 18 fevereiro 2010.

BARRETO, Margarita. Manual de iniciação ao estudo do turismo. $6^{\mathrm{a}}$ ed. Campinas, SP: Papirus. (Coleção turismo). 1995. 164p.

BERTRAND, Georges. Paisagem e geografia física global. Esboço Metodológico. Revista RA'E GA - O Espaço Geográfico em Análise. nº 8. Curitiba: EdUFPR. 2004. p.141-152.

BOUllón, Roberto C. Planejamento do espaço turístico. Tradução Josely Vianna Baptista. Bauru, SP: EdUSC, 2002. 278p. 
BOLSON, Jaisa H. Gontijo. 2004. A importância da paisagem na atividade turística. Disponível em: www.revistaturismo.com.br/artigos/paisagem.html. Acesso em: 15 setembro 2010.

CARLOS, Ana Fani Alessandri. O turismo e a produção do não - lugar. In: YÁZIG, Eduardo, CARLOS, Ana Fani Alessandri, CRUZ, Rita de Cássia Ariza da. (Orgs). Turismo: Espaço, paisagem e cultura. São Paulo: Hucitec. 1999. p.25-39.

CASTRO, Iná Elias de. Paisagem e turismo. De estética, nostalgia e política. In: YÁZIG, Eduardo. Turismo e paisagem. São Paulo: Contexto. 2002. 228p. p.121-140.

CORIOLANO, Luzia Neide Menezes Teixeira. O real e o imaginário nos espaços turísticos. In: CORRÊA, Roberto Lobato.; ROSENDHAL, Z. (Orgs.). Paisagem, imaginário e espaço. Rio de Janeiro: EdUERJ. 2003. p. 207-227.

CRUZ, Rita de Cássia Ariza. As paisagens artificiais criadas pelo turismo. In: Turismo e paisagem. São Paulo: Contexto. 2002. 228p. p.107-119.

FERNANDES, Nelson Ferreira. Seminário "Ilha Grande: Aspectos geomorfológicos e uso/ocupação do solo". Clube de Engenharia - CREA/RJ. Realizado em 27 janeiro 2010. Comunicação oral.

FERNANDES, Nelson Ferreira; AMARAL, Cláudio Palmério. Movimentos de Massa: Uma abordagem geológica-geomorfológica. In: GUERRA, Antonio José Teixeira; CUNHA, Sandra Baptista. Geomorfologia e meio ambiente. Rio de Janeiro: Bertrand Brasil. 2006. 394p. p. 123-194.

FONSECA, Maria Aparecida Pontes. Espaço, políticas de turismo e competitividade. Natal: Editora de UFRN (EdUFRN). 2005. 226p.

FRANCISCO, Cristiane Nunes; CARVALHO, Cacilda Nascimento. Disponibilidade hídrica - da visão global às pequenas bacias hidrográficas: $\mathrm{O}$ caso de Angra dos Reis, no Estado do Rio de Janeiro. Revista Geociências, Niterói: Instituto de Geociências. ano 3, $\mathrm{n}^{\circ} \quad 3$, 13p. 2004. Disponível em: www.professores.uff.br/cristiane/.../ Art\%20rev\%20geo\%20-\%20final\%20revisada\%20completa.pdf. Acesso em: 25 janeiro 2010.

FUNDAÇÃO DE TURISMO DE ANGRA DOS REIS - TURISANGRA. Disponível em: www.turisangra.com.br. Acesso em: 28 janeiro 2010.

GONTIJO, Bernardo Machado.; REGO, Jackson Fernando. Por uma atitude turística pessoalizante. In: FARIA, Ivani Ferreira. (Org). Turismo: sustentabilidade e novas territorialidades. Manaus: Editora da Universidade do Amazonas (EdUA). 2001. p. 116.

GUERRA, Antonio José Teixeira.; MARÇAL, Mônica dos Santos. Geomorfologia aplicada ao turismo. In: GUERRA, Antonio José Teixeira.; MARÇAL, Mônica dos Santos. Geomorfologia ambiental. Rio de Janeiro: Bertrand Brasil. 2006. 192p. p. 42- 
46.

IGNARRA, Luiz Renato. Fundamentos do turismo. $2^{\text {a }}$ ed. São Paulo: Pioneira Thomson. 2003. 205p.

INSTITUTO BRASILEIRO DE GEOGRAFIA E ESTATÍSTICA - IBGE. Disponível em: www.ibge.gov.br. Acesso em: 25 fevereiro 2010.

INSTITUTO VIRTUAL DE TURISMO - COPPE/UFRJ. Disponível em: www.ivtrj.net. Acesso em: 27 fevereiro 2010.

MENESES, Ulpiano Toledo Bezerra. A paisagem como fator cultural. In: Turismo e paisagem. São Paulo: Contexto. 2002. 228p. p. 29-64.

MINISTÉRIO DE RELAÇÕES EXTERIORES (M.R.E). O Estado do Rio de Janeiro. Disponível em www.dc.mre.gov.br/imagens-e-textos/revista1-mat9.pdf. Acesso em: 10 janeiro 2010.

MOLINA, Sérgio. Turismo e ecologia (Tradução Josely Vianna Baptista). Bauru, SP: Editora da Universidade do Sagrado Coração (EdUSC). 2001. 234p.

OLIVEIRA, Antonio Pereira. Turismo e Desenvolvimento: Planejamento e Organização. $3^{a}$ ed. São Paulo: Atlas. 2001. 293p.

PREFEITURA DE ANGRA DOS REIS. Disponível em: www.angra.rj.gov.br. Acesso em: 09 dezembro 2009.

PREFEITURA DE ANGRA DOS REIS/DEFESA CIVIL. Disponível em: http://www.angra.rj.gov.br/ defesacivil. Acesso em: 10 maio 2010.

RIBEIRO, Miguel Angelo. Tipologia das atividades turísticas: o exemplo do Estado do Rio de Janeiro. Revista Geo UERJ, Rio de Janeiro, ano 6, v. 1, n. 13, p. 27-37, jan./jul. 2003.

RODRIGUES, Arlete Moysés. A produção e o consumo do espaço para o turismo e a problemática ambiental. In: Turismo, Espaço, Paisagem e Cultura. São Paulo: Hucitec. 1996. 241p. p. 55-62.

SALGADO, Carla Maciel; PEIXOTO, Maria Naíse de Oliveira; MOURA, Josilda Rodrigues Silva. Caracterização espaço-temporal da chuva como subsídio à análise de episódios de enchentes no município de Angra dos Reis, RJ. Revista Geosul, Florianópolis, v. 22, n. 44, p 7-26. jul./dez. 2007.

SILVA, Telma Mendes. A estruturação geomorfológica do Planalto Atlântico no Estado do Rio de Janeiro. 265f. Tese (Doutorado em Geografia) - Instituto de Geociências, Universidade Federal do Rio de Janeiro, 2002. 
SOARES, Erika Leite de Souza Ferreira; SILVA, Telma Mendes. Avaliação das potencialidades turísticas no Estado do Rio de Janeiro: base para uma proposta de zoneamento. In: SIMPÓSIO BRASILEIRO DE GEOGRAFIA FÍSICA APLICADA - A Geografia Física e as Dinâmicas de Apropriação da Natureza, 13º 2009, Viçosa. Cdrom... Viçosa: Universidade Federal de Viçosa, Depto. de Geografia, 2009. 15p.

TURISRIO - Companhia de Turismo do Estado do Rio de Janeiro. Disponível em: www.turismo.rj.gov.br. Acesso em: 15 fevereiro 2010.

YÁZIGI, Eduardo. A importância da paisagem. In: YÁZIG, Eduardo. Turismo e paisagem. São Paulo: Contexto. 2002. 228p. p. 11-28. 